\title{
Guiding Preservice Teachers to Making a Shift in Thinking: Developing Skill and Confidence in Assessment through Thematic Integrated Units
}

\author{
Porter E. Coggins III, Linda K. Colburn \\ Department of Professional Education, Bemidji State University, Bemidji, USA \\ Email: Porter.Coggins@bemidjistate.edu,Linda.Colburn@bemidjistate.edu
}

How to cite this paper: Coggins III, P. E., \& Colburn, L. K. (2018). Guiding Preservice Teachers to Making a Shift in Thinking: Developing Skill and Confidence in Assessment through Thematic Integrated Units. Creative Education, 9, 1485-1503. https://doi.org/10.4236/ce.2018.910110

Received: May 5, 2018

Accepted: August 4, 2018

Published: August 7, 2018

Copyright (c) 2018 by authors and Scientific Research Publishing Inc. This work is licensed under the Creative Commons Attribution International License (CC BY 4.0).

http://creativecommons.org/licenses/by/4.0/

\begin{abstract}
In this paper we present our journey as elementary education methods course instructors through a practical action research design refining a model thematic integrated unit for our preservice teachers in an elementary education methods course and how we revised our model unit to incorporate the assessment cycle in our model unit. We present our initial model thematic integrated unit encompassing language arts, history, mathematics, and science, our initial model unit lesson, our concerns with that unit lesson, our insight with respect to the missing component of the assessment cycle in our model unit lesson, and how that insight connects to our education of philosophy and teacher education program prerequisite courses. Successful teachers must be able to analyze student assessment data in order to meet the individual needs of all students. Our preservice teachers were asked to evaluate two sets of hypothetical student assessment data in order to identify the learning objectives that needed to be revisited. From their analysis, they broke into small-group pull-out sessions, taught the reteaching lessons based on their analysis of the hypothetical student data, and reassessed learning objective competency. Thus, our preservice teachers were allowed to experience the plan-teach-assess-reflect model necessary for their own individual journey toward becoming a successful professional educator.
\end{abstract}

\section{Keywords}

Elementary Education Preservice Teacher Education, Assessment, Pedagogy, Modeling Thematic Integrated Lesson Planning, Constructivism

\section{Introduction}

In this paper we present our journey as elementary education methods course 
instructors through a practical action research design refining a model thematic integrated unit for our preservice teachers in an elementary education methods course and how we revised our model unit to incorporate the assessment cycle in our model unit. For several years, two of the methods course instructors in the elementary education program have collaborated and team-taught a thematic integrated unit titled in class as The Freedom Quilt. This model unit integrates social studies, science, language arts, and mathematics around freedom quilts during the slavery era (1619 to 1865) in the United States. This unit was typically presented within the first three weeks of the semester. Prior to presenting the freedom quilt unit in class, we explained that our time-frame for completing this unit was one four-hour block session, in contrast to an actual unit implementation that might last for weeks or one or more academic year quarters depending on the curricular approach. While not overtly stating state standards, our learning objectives sufficiently covered specific state standards, our preservice teachers will be required to address as licensed teachers in our state, and we typically couched the learning objectives in general terms of learning outcomes and evidence they will be providing throughout the unit. By the end of the unit, students had, in the role of elementary school students, read and discussed the picture book Sweet Clara and the Freedom Quilt by Sarah Hopkins (1995), investigated major events related to slavery in the history of the United States between approximately 1619 and the end of the Civil War, created timelines with color coded maps indicating free states and territories compared to slave states and territories during that time period, investigated phases of the moon, aspects of plants and vegetation in general and particular to southern states in the United States, and typically ended the lesson after students created freedom quilts based on mathematical symmetry. We worked at a purposeful speed in class and periodically during transitions reminded our preservice teachers that we were very quickly doing an entire unit in our condensed four-hour time-frame in class in contrast to a more realistic calendar schedule that they might follow as teachers in elementary school classrooms.

\section{Methods}

\subsection{Methodology}

We employed a practical action research design for this qualitative study (Creswell, 2015) as the appropriate design to address our research problem and questions. Creswell defines purpose of practical action research as "Teachers seek to research problems in their own classrooms so that they can improve their students' learning and their own professional performance" (Creswell, 2015: p. 281), and Plano Clark and Creswell describe the process once the focus has been determined as a "cycle of reflecting, data collection, and taking action" (Plano Clark \& Creswell, 2015: p. 432). Institutional Review Board (IRB) permission was granted for this study. 


\subsection{Participants and Context}

We conducted this study over the course of four semesters in a combined elementary education major methods course covering language arts, science, social studies, and mathematics. Our course met Monday through Thursday for four hours each day. The students in this course were seniors who typically progress to student teaching in the following semester. All participants signed an informed consent per institutional IRB policy.

\subsection{Research Problem}

Identify the missing component in our Freedom Quilt unit necessary for a more complete understanding of all of the components required of a successful unit lesson with respect to stated learning objectives.

\subsection{Research Questions}

1) What might be missing from our model Freedom Quilt thematic unit?

2) What learning objectives do we want our model Freedom Quilt unit to meet?

3) How does our model Freedom Quilt unit serve as a foundation learning objective expectations for other thematic integrated units in our course?

\section{Review of the Literature}

Unravelling our research questions required consideration of our philosophy of education, our concept of team teaching, our understanding of the effects of prior experience of our preservice teachers in their professional education courses, the differences between understanding and action of novices compared to experts, our understanding and intent of the use of thematic integrated units, and the purpose and scope of assessment.

\subsection{Constructivist Philosophies of Education and Brain Imaging}

In our teacher education program, the department faculty individually adopted various versions of constructivist philosophies of education. Although these philosophies been framed in several ways as indicated below, a common intersection of the definitions includes the notion that individuals engage in interaction with their surroundings in order to make connections to their own prior knowledge in order to grow in their own deeper understanding of their surroundings. As learners, we need to be actively engaged in the process of constructing and connecting, not passively receiving information. Although there are many perspectives on constructivist approaches to learning, we provide three for reference with which to interpret our journey. Noddings provided a principled definition of constructivism that includes the tenets "1) All knowledge is constructed... 2) There exist cognitive structures that are activated in the process of construction. These structures account for construction... 3) Cognitive structures are under continual development. Purposive activity induces transforma- 
tion of existing structures. The environment presses the organism to adapt" (Noddings, 1990: p. 10). Confrey has defined constructivism as "We construct our understanding through our experiences, and the character of our experience is influenced profoundly by our cognitive lenses" (Confrey, 1990: p. 108). Von Glasersfeld provides a definition of constructivism in which "... (1) knowledge is not passively received, but actively built up by the cognizing subject, (2) the function of cognition is adaptive and serves the organization of the experiential world, not the discovery of ontological reality" (von Glasersfeld, 1989: p. 114). With those definitions in mind, we acknowledge the neurobiological foundation which allows us to make meaning of our world. Neuroimaging techniques have expanded our understanding of the biological basis for many cognitive processes including memory and memory systems functionality (Buckner \& Koutstaal, 1998; Scimeca \& Badre, 2012), overall cognitive processing (Bennett \& Rypma, 2013), and semantic processing (Fedorenko et al., 2016), as well as overall brain development (Bennett \& Madden, 2014; Giedd et al., 1999; Hasan et al., 2009; Jakab, Tuura, Kellenberger, \& Scheer, 2017; Keshavan et al., 2002; Madden et al., 2012; Qiu, Mori, \& Miller, 2015; Tanaka-Arankawa et al., 2015), and have demonstrated the interconnectivity between regions of the brain including the corpus callosum (Coggins, 2002; Hasan et al., 2009; Jakab, Tuura, Kellenberger, \& Scheer, 2017), the internal capsule and cerebral peduncle (Park et al., 2008), and ipsilateral hemispheric fasciculi (Jellison et al., 2004; O’Donnell et al., 2006). Thus, modern neuroimaging of the brain demonstrates the complex interconnectivity of brain regions responsible for constructing our understanding of the world as we develop and experience the world and offer a biological basis for constructivist philosophies.

\subsection{Team Teaching}

Our elementary education major language arts, science, mathematics, and social studies methods courses have typically been offered as stand-alone courses, as done in many universities. Several years ago, our methods instructors embarked on a project to integrate these methods courses under a set of unifying, integrated themes and delivered as a single course with four course instructors. Previously, Bakken, Clark, and Thompson (1998) shared their experience in developing an integrated, co-taught course built from three different courses. They were purposeful in their desire to collaboratively build a single course from three separate courses that would truly integrate content from all three stand-alone courses and construct it in such a way that the content of the three courses would complement each discipline creating a whole greater than the parts. In addition, they reported the professional value of participating in a collaborative experience. As Bakken, Clark, and Thompson found we too noted the professional value as well as a powerful learning experience for out preservice teachers when we remodeled our methods courses under a single course with integrated, unifying thematic units. Jenkins and Crawford (2016) used an action research 
cycle of reflect, plan, act, observe, repeat (the cycle) in developing their course with both faculty members collaborating on all aspects of course construction. Implementation typically involved both instructors in the class with one assigned to lecture while the other was assigned as the observer, with some classes devoted to "interactive team teaching" (p. 8). Although unaware of the research reported by Jenkins and Crawford, we too were able to both create a course environment with principle co-teachers and observer/note takes for our after-class debriefing sessions that we conducted in our faculty offices multiple times each week and engage in the action research cycle. This collaboration process in both planning and debriefing consistently lead us into very deep water philosophically, pedagogically, and professionally. Lester and Evans (2009) describe their approach to team as a process of co-planning, co-ownership of understanding the information being presented, and co-presence with both in class together. Their commitment to collaborative teaching is summed up "Based on our core belief that knowledge was more than the sum of individual ideas, we determined that our approach to team teaching must extend beyond the idea of occasionally teaching together to always teaching together" (p. 375) and made the extremely insightful comments "One avenue through which teachers may gain insight into this approach is through walking in the shoes of the team teachers who engage in this practice" (p. 375). Weiss, Pellegrino, Regan, and Mann (2015) related three phases of collaborative teaching in the context of course construction that included consideration of collaboration, commitment to the process of collaboration, and commitment to each other. They noted that "Every aspect of the course design was negotiated with collaboration in mind" (p. 98), and "The construction of the course and all class assignments were done purposefully to encourage collaborative practice..." (p. 98). We too found that commitment among the four of us was essential for success and as such, we made deep sacrifices to other obligations in order to "build this airplane in flight" as we often said in our regular planning and debriefing sessions. Wilson and Martin (1998) developed a team-taught course integrating science, social studies, and mathematics for elementary school majors that incorporated both discipline-specific instruction time as well as time devoted to an integrated view of the disciplines. Further, they shared their transition from simply alternating instruction time in class to a true synergistic co-teaching model with both instructors feeding off of each other in various roles of classroom instruction among the roles of talk-write, model-comment, present-elaborate, and they are both leading the class (p. 5).

\subsection{Prior Experience versus Formal Teacher Education}

Due to the compartmentized curricula pervasive in public education in the United States, prior learning experience in grades K-12 for preservice teachers in teacher education programs in the United States may have resulted in the learning of discrete and disconnected facts and information unless they have been allowed opportunities to identify relationships and connections among the infor- 
mation learned. Further, preservice teachers may have developed preconceptions about teaching and learning based on the past 12 or more years of their education journey (Hammerness, Darling-Hammond, \& Bransford, 2005). So, it is not surprising, and must be expected that preservice teachers will likely have to wrestle with their own preconceptions and misconceptions. Making this shift from a compartmentalized curricula to a thematic integrated curricula will require that they begin to think in ways that challenge their old patterns of thinking. In an effort to help our preservice teachers shift their thinking from the way that they were taught to a new model of learning and teaching, we ask them to think more holistically, to make connections between as many bits of information they encounter in our course and as often as possible, and to approach thinking about teaching and learning, as well as curriculum, from a more integrated perspective. However, in spite of the possibility of deep understanding of everything required of a successful professional educator, preservice teachers are still novices in the profession if for no other reason than the lack of wisdom, which only experience and time may provide, and this combination of deep understanding and experience-dependent wisdom in part separates the novice professional educator from the expert.

\subsection{Implications of Expert versus Novice in Teacher Education}

Preservice teachers are not experts in spite of the fact that they might think they are or in spite of expectations placed upon them as graduates from a teacher licensure program. We recognize that there are differences between the thinking skills of experts compared to novices. In a general context, Shanteau (1992) lists attributes of an expert including domain knowledge, psychological traits, cognitive skills, decision strategies, and task characteristic. Other differences between novices and experts include differences in memory use (Chase \& Ericsson, 1981), in solving geometry proofs (Anderson, Greeno, Kline, \& Neves, 1981), in problem solving (Jeffries, Turner, Polson, \& Atwood, 1981), and in the game of chess (de Groot, 1946). More recently, Sheridan and Reingold noted that “...experts are faster at detecting relevant information than novices..." (2014: p. 4). Benner noted in the context of nursing that the expert nurse "...has an intuitive grasp of the situation and zeros in on the accurate region of the problem without wasteful consideration of a large range of unfruitful possible problem situations" (1982: p. 403). Persky and Robinson (2017) made a keen observation that automaticity does not imply expertise. In fact, automaticity built from incomplete or misconceptions is problematic on many levels and is important for our preservice teachers to understand. Perksy and Robninson noted the difference between novice and expert level of pattern recognition and suggested the need to provide opportunities to help novice learners learn to "see patterns" (2017: p. 76) through a variety of scaffolded activities. Previously, Bransford, Brown, and Cocking (2000) noted that preservice teachers need guidance in attending to patterns in student work, that they see things through the eyes of a novice and that they will not attend to details in the same way that an expert 
would. In teacher education, this difference between novice and expert is uncovered in artifacts preservice teachers complete in a variety of informal and formal assessments. For example, despite possibly great general knowledge of discrete facts, preservice teachers are preprofessional novices still learning to synthesize and assemble bits into meaningful wholes that provide an accurate conceptual model from which to make teaching-judgments, and to analyze information to separate wheat from chaff in the context of even determining their own level of competence and mastery of learning objectives. They tend to both overestimate the depth in their understanding of complex information, and yet underestimate what it takes to deepen their understanding as do all who are still developing their competence (Kruger \& Dunning, 1999). On principled grounds, this would seem to be especially true for those aspects of teaching of which our preservice teachers have the least experience such as assessment. Maclelan (2004) affirmed that indeed, preservice teachers do have an incomplete understanding of assessment, and that there is a need for teacher training programs to attend to this lack of understanding. Remesal states that teachers' conceptions of the function of assessment may be fostered by contrasting beliefs about assessment (2011) fostered by the lack of experience and deep reflection about assessment.

\subsection{Supporting Connection-Making with Integrated Learning}

Thematic, integrated lessons and units offer preservice teachers the opportunity to engage in multiple learning objectives concurrently in the context of multiple entry points to content, and as well provide an opportunity to experience that content in ways consistent with what is known and believed about how the brain makes connections from both neuroimaging studies and constructivist philosophies of education. With respect to curricula and instruction, teacher resources for integrating discrete content areas into a unified whole can be found in Ward (2009), Barta, Eglash, and Barkley (2014), and Ansberry and Morgan (2010), among other sources. Preservice teachers who are allowed to experience knowledge in a broad context of thematic integrated units are able to see how content information in one discipline is related to, affects, and is affected by, content information in another discipline. In turn, this opportunity to engage in course content from this multidimensional aspect allows them to create deeper mental representations. Because content (knowledge) in an integrated unit has multiple points of contact, students have multiple hooks for recall and use in the context of other higher order thinking (Anderson et al., 2001; Davachi \& Dobbins, 2008). For example, John (2015) found preservice teachers trained to use integrated lessons had statistically significant differences (improvement) on several measures of teacher and student performance along with higher teacher self-efficacy compared to those teachers not trained to use integrated lessons. Integrating content in cultural contexts has important theoretical and cognitive value. Bishop (1988), Kline (1962), Vygotsky (1978), Luria (1976), Cole and 
Scribner (1974), Cole, Gay, Glick, and Sharp (1971), Saxe (1991), and Whorf (1956) for example, have written extensively on the connection between culture and cognition. Providing opportunities for preservice teachers to engage in culturally relevant integrated lessons can help lead them to make a shift in thinking from isolated facts to deeper concept development (Smagorinsky, Cook, \& Johnson, 2003). However, reaching toward our goal of leading our preservice teachers to make that shift required ongoing deep reflection and conversation. Part of helping our preservice teachers make that shift includes modeling thematic integrated lessons for them as we have explained below.

\subsection{The Importance of Assessment}

Teacher education is a professional program consisting of both theoretical and practical components that enables successful students to graduate with a license to work in an educational setting. In the United States, the Every Student Succeeds Act (ESSA, 2015) signed into law in 2015 reauthorized the Elementary and Secondary Education Act (ESEA, 1965) and, among other issues, raised the academic standards for students, mandated access to quality education for all, and as well raised teacher preparation standards. Many university teacher education programs have been directed by their state boards of education and state legislatures to adopt assessment tools (such as the Praxis tests, edTPA, or other licensure proficiency examinations) to ensure rigorous teacher preparation. However, even with preparation afforded in university teacher education degree programs, it is possible, and indeed likely, that preservice teachers may not fully understand the value and importance of using student assessment as a tool for re-teaching. This is not surprising, as many other scholars and educators have remarked on preservice teachers' difficulty in understanding the purpose and potential of assessment (Bransford, Brown, \& Cocking, 2000; Hammerness, Darling-Hammond, \& Bransford, 2005; Remesal, 2011). Indeed, we have noticed this incomplete understanding of assessment from preservice teachers in our integrated methods courses at our institution at the beginning of each term.

\section{Our Journey to the Epiphany}

\subsection{Identification of the Missing Component}

Several years ago, based on a model used previously by one of the methods instructors at another university, students were asked to individually construct and teach in class a lesson plan that integrated at least two other content area disciplines. This model was used in the elementary education math methods course at this university by the math methods instructor and introduced when the methods courses were combined into one thematic integrated course. After the conclusion of this thematic integrated unit after the first several semesters in both the stand-alone and combined methods course, once the Freedom Quilt unit was presented and students taught their individual lessons, this thematic integrated unit topic was behind to evaporate in the course and be replaced in 
the students' mental space with the next item on our course syllabus to-do list. Once we combined our methods courses, we (the course instructors) were in the habit of meeting as soon after class as possible to debrief on what went well, share insights, and consider what we might adjust for the next semester. This was a valuable opportunity that was not readily available when each methods course was taught in isolation because without experiencing the thematic integrated unit, it was not quite possible to grasp subtleties nor offer constructive critique on improvement of this model unit. But, once the courses were combined, we had the opportunity and the commitment to debrief regularly. In that context, one course instructor regularly expressed an unsettled feeling at the conclusion of the Freedom Quilt unit, that something was still missing from the experience. The parts seemed to be there (but were they really?), and we did what we set out to do (but did we really?), but something was still missing (or not?). We carefully modeled this thematic integrated unit for our students, but still, something was missing. Some critical, nebulous, hauntingly important piece seemed to be missing. What was it?

Early in the education program, preservice teachers are introduced to the plan-teach-reflect cycle and are reminded of both the saying failure to plan is planning to fail and the aviation acronym CFIT, controlled flight into terrain. CFIT refers to an aviation accident which is essentially the result of pilot error where the pilot, with hands on the controls of a properly working aircraft, makes an error which results in flying the aircraft into the ground (Federal Aviation Administration, 2003). By reminding students of these two critical points to remember, we hope to make a lasting impression on preservice teachers regarding conscious and conscientious planning, and the importance of the stakes involved as a licensed professional educator. With that in mind, preservice teachers in our program are given the opportunity through the duration of their degree experience to construct lesson plans under faculty guidance. In particular, during the methods courses, students are given the opportunity to make multiple integrated lesson plans.

We had been overtly modeling the teach aspect of the plan-teach-reflect cycle in the Freedom Quilt unit, and prior to presenting this unit, we had discussed with the class the plan aspect (even if incompletely), and while we always spoke of assessment as part of this process, it became clear to us that we were not clear enough about our expectations (in part because we were not sure what we expected ourselves). As such, in the beginning, our learning objectives were that students would be able to create a thematic integrated unit plan upon completion of this model Freedom Quilt unit. Although we asked them to demonstrate effective unit planning, we did not require our preservice teachers to show us what they understood about assessment. That (assessment) was the missing ingredient and it became evident in a debriefing session after guiding our preservice teachers through the Freedom Quilt unit. It was no apparent that we needed to make this aspect of the cycle much more explicit and transparent. And with 
that insight, we recognized that our preservice teachers would need additional scaffolding in order to make this transition and develop their abilities to truly use assessment to inform and plan for instruction. Once we did that, our learning objective likewise was modified to include an overt component of assessment.

Regarding fellow teachers, Morrison admits "...data as a resource that helps them teach better; many experience it as unfamiliar or threatening" (2008/2009, Para. 1). However, helping preservice teachers deepen their understanding of assessment has been noted as both important and easier said than done. For example, Reeves (2009) noted an important aspect of assessment in which teachers move beyond an instant assumption without deeply reflecting on the implications of assessment data and jumping directly into a skill-building post-assessment strategy based on an incomplete determination of scores rather than a determination of the underlying issue of aspects of performance assessment, regardless of the assessment score. Reasonably, this is a likely strategy that a novice teacher might employ upon seeing student assessment data when they lack the expertise to think otherwise. Further, Chappuis noted "It's not enough to know that students haven't mastered something yet-it's also important to know the type of problem that is standing in the way of mastery so that we can plan appropriate next-step instruction" (2014: p. 23). But, knowing what to do is not the same as knowing how to do it, according to Goertz, Olah, and Riggan (2009). The teacher must identify patterns in assessment data, and then use that information to plan for follow-up instruction for those students who need more time or support to reach the learning objectives. We again refer to the literature on expert and novice learning, acknowledging that "experts notice features and meaningful patterns of information" that novices do not (Bransford, Brown, \& Cocking, 2000: p. 31) and that our preservice teachers, who are clearly novices, must have opportunities to recognize these meaningful patterns of information and must be supported in developing the kinds of organized understanding and skills, which will lead to greater self-confidence in their own ability to take effective action (2000: p. 36). It became clear to us that our plan-teach-reflect cycle must be reframed to plan-teach-asses-reflect.

\subsection{Closing the Loop: Exploring Patterns in Student Data}

In conversation, we expressed a shared understanding of the necessity of providing our preservice teachers with the opportunity to reflect on the what next which was an identified weakness of their final analysis. We wrestled with the breadth vs. depth question that all teachers must balance, and depth won. We set aside more time in class to prepare students for the data analysis and the thinking about reteaching. We also recognized the need to allow our preservice teachers dynamic involvement in the unit as teachers. In the second iteration, we provided both more time and more scaffolding for the data analysis. We walked the preservice teachers through the plan-teach-assess-reflect cycle and worked 
initially as a class to think through the iterative nature of this process. So, over several semesters we transitioned from a whole-class discussion on general aspects of assessment to the opportunity to analyze hypothetical student data in small groups and the development of a reteaching lesson based on a misconception or error they noted in the data set. Although our preservice teachers were clearly moving in the right direction based on our analysis of their reteaching lesson plans and simulated small pull-out reteaching, we wanted to have them dig deeper still, and allow them to take more ownership in the entire process from data analysis to reteaching with continued assessment analysis.

To that end, we asked them to work in pairs and conduct an in-depth analysis for all eight hypothetical-students, being specifically instructed to look for patterns and opportunities to group students. They were then asked to write up an analysis for all the students and then identify a draft of a plan for those students they would pull out for intervention. At this point, we emphasized the need to refrain from reteaching the same way the content was taught in the whole-class instructional method, but rather, take into account that these hypothetical students hit a learning roadblock in part due to the original instructional method, and hence they should plan the reteaching using a different instructional strategy that was appropriate to the small pull-out group and also different from the first instructional approach that lead to the assessment they had analyzed. We allowed additional time for this process and for the preservice teachers to make use of the feedback we provided, prior to completing their lesson plan. This time, the initial analysis was stronger, and the final discussion of their reteaching included plans for those hypothetical students, as we hope they would for their future students, who might need additional support akin to possibly a Response to Intervention (RTI) Tier III intervention approach. We did not want ongoing assessment to stop after simply reteaching but emphasized to our students that a single-shot reteaching is not a magic pill and possibly further intervention could be required in order to allow all students to master the learning objectives. We knew we were on a better track and instead of just talking about the importance of assessment, we had taken the time to methodically and purposefully walk our preservice teachers through the iterative process, so that they could construct their own understanding of the process-not just hear how others had done so-and in doing this, our preservice teachers were making greater progress towards putting on their teacher hats and making that shift from student to teacher.

\section{Conclusion}

As we reflected on our journey, several points stuck out to us that are worth elaboration: prompting assessment based on student data, providing preservice teachers with the opportunity to analyze student data for instruction, leading preservice teachers to deepen their understanding of the iterative nature of data use for instruction, helping preservice teachers connect the dots, and implica- 
tions for teacher education. We modeled teaching a thematic integrated lesson on Freedom Quilts from the slavery period in the United States for our elementary education preservice teachers in a constructivist framework, and then switched perspective at the end of the lesson allowing them to role play the part of the teacher in order to analyze fictitious student assessment data for the purpose of replanning and reteaching to help these fictitious students meet the unit lesson learning objectives. We recognize the steep learning curve to move from a novice teacher to an expert teacher, and that there are practical steps we can, and are taking, to help our preservice teachers secure sound footing on that path. We did this in our courses by asking our students to consider two sets of hypothetical student assessment data, examine and sort the data based on emergent patterns, develop a reteaching lesson plan appropriate to meet the specific needs of the specific patterns our preservice teachers identified, and to deliver and reflect on the outcome of that lesson. The goal is to help preservice teachers see the iterative nature of assessment and to learn to use the data to help plan future instruction. Although this was one small step on the road to becoming an expert professional educator, it was an important step, and we hope our experience described here may be beneficial for others in university teacher education programs.

\subsection{Prompting Preservice Teachers' Data Analysis for Assessment}

Becoming a teacher who is prepared to effectively orchestrate the learning environment requires the development of many skills. There is international awareness that this is a complex process and one that requires high quality learning experiences both in the college classroom and in the field (Hattie, 2003). This awareness is also evidenced in the global rise in Quality Assurance and Accreditation (Accreditation as Quality Assurance, 2013; Jackson \& Bohrer, 2010; Ryan, 2015; U.S. Department of Education, 2008). Concurrently, there are numbers of different tools that are being used to measure preservice teachers' readiness to teach in classrooms and schools. In the United States, for example, many teacher education programs have recently adopted (2014) the edTPA as a performance assessment, which is now being used to measure the readiness of student teachers to plan, teach, and assess in the classroom. Student teachers from our institution typically perform better on the plan and teach segments of the tool than they do on the elements related to assessment. The data from the past three years of our participation in this process has served to corroborate our concern, as instructors and as a department, that assessment was an area that needed additional focus and greater opportunities for our preservice teachers to develop expertise. It will likely be several performance assessment cycles at our institution before we have sufficient data to examine a possible correlation between our work with this integrated thematic lesson and edTPA scores, but regardless, it is important that preservice teachers have a conceptual understanding of assessment for learning and procedural knowledge of implementation of ongoing as- 
sessment for learning as we modeled in our Quilt unit.

\subsection{Providing Opportunities to Dig Deep Using Data for Instruction}

We recognize that our plan-teach-assess-reflect cycle was a singular attempt at what needs to be a much more concerted effort across the curriculum in our department and in our methods courses. In our department, we have considered where we want out students to be with the conceptual understanding of the scope of planning, teaching, and assessing in prior coursework before taking the methods courses and what we want them to know in order to be able to hit the ground running with our Freedom Quilt unit and related learning objectives regarding assessment. In our methods courses, we have since added an additional lesson that is meant to be taught during the field experience, with actual students. This lesson also has an assessment and review/reflection component where preservice teachers must consider what to do next as we modeled and asked our students to practice in class in the Freedom Quilt unit.

\subsection{Deepening Understanding of the Iterative Nature of Assessment}

School administrators and others, who are responsible for the analysis of large data sets related to student progress, advocate for new incoming teachers to have a deeper understanding of how to disaggregate data and an understanding of how to use the analysis to help plan for future instruction. This is a need in all school settings and thus our preservice teachers must begin to develop this expertise and to have an ongoing view of data rather than seeing it as an end set. Our Freedom Quilt unit is one example of how we are striving to meet that need.

\subsection{Helping Preservice Teachers Connect the Dots for Instruction}

We know from a constructivist philosophical perspective that information is meaningful only when connected meaningfully. We know from the literature that experts are faster and more efficient in sorting out irrelevant information from relevant than novices, and that experts are better at detecting patterns in information than novices. We know that preservice teachers have not yet had the experiences that expert teachers have in the classroom, and we know preservice teachers are charging up the learning-curve hill of learning the intricacies and complexity required of their profession including effective assessment use and analysis. Thus, providing preservice teachers with multiple opportunities to practice looking at, sorting, and planning based on assessment data is important for helping them learn to tune their teacher-eyes to see what each student needs in order to meet stated learning objectives.

\subsection{Implications for Teacher Education}

Accrediting bodies have called on teacher education to step up our programs to provide new teachers with the skills they need in order to be successful in the 
classroom. We understand that having the confidence and strategies to successfully approach assessment and instruction is one of many areas where we need to build novice teacher expertise. We have clearly witnessed the growing confidence in those preservice teachers who engaged in this experience and we have noted increased strength in this area, but we also recognize that our Quilt unit is just one small but important step in this process of leading our students to deeper understanding of the depth of skills necessary to become an expert professional educator.

\subsection{Looking Back}

In retrospect, we consider the degree to which we answered our original research questions stated above. We employed a practical action research design, although we did this naturally and unconscious of the overt nature of the process, likely due to our prior background knowledge of the process and our experience at teachers. Consistent with the practical action research cycle, we identified the focus as the question of what might be missing from our unit model Freedom Quilt. Our question was based on after-class discussion regarding the depth of our lesson from our personal reflection. This was the first data set used in the practical action research cycle. Upon reflection, our unit was clearly missing any opportunity for our preservice teachers to deeply reflect on the process of the unit. On our next pass teaching this unit in the following semester, we asked our students to engage in a whole-class discussion on the unit process. Based on that discussion, we still felt something was missing and continued to discuss this unit in our after-class debriefing. We then determined that we needed to further engage our preservice teachers in the importance of assessment as a pedagogical tool for helping all students meet unit learning objectives. We did that by asking our students to consider hypothetical student data based on specific content of the Freedom Quilt unit modeled in class, the plan a reteaching based on patters they discovered in the data, and to actually teach the lesson to small groups of classmates who role-played as elementary school students. This was nearly right on the mark with respect to our intentions for this unit. Again, after reflection on based on triangulation of our review of preservice analysis of the data sets, intended reteaching lesson, and actual reteaching of the lesson, we determined we could still lead our students into deeper understanding by allowing them the opportunity to develop a written reflection on the plan-teach-assess cycle that they participated in. So, as course instructors using the practical action research cycle, we finally arrived at a place in our journey where we are confident our preservice teachers have the opportunity to fully and completely engage in a rich thematic integrated unit comprised of all aspects of the plan-teach-assess-reflect cycle necessary for professional educators. Although they are not yet experts, they are now on the right path that will lead to becoming an expert education once they continue this process in their own classrooms.

Our learning objectives evolved in this process from simply being able to 
create a thematic integrated unit based on our model Freedom Quilt to creating a thematic integrated unit with a specific reteaching lesson based on patterns and misconceptions identified from the hypothetical student data sets and providing well-developed reflection on the reteaching based on the analysis of the data.

Solving the puzzle of the missing component in the Freedom Quilt has allowed us to effectively close the loop in all of our other thematic integrated units we teach in our course. We are in the process of creating hypothetical data sets for the other units and follow the template we have developed in the Freedom Quilt to allow are preservice teachers continued opportunities to plan reteaching based on analysis of hypothetical student assessment data to better prepare them for their careers as professional educators that is swiftly coming around the bend as they complete their undergraduate degree and state teaching license.

Although not a research question, we are grateful to have completed this journey as co-teachers team teaching this methods course. Our daily debriefing after class allowed us the opportunity to continue to reflect on, dialog about, and co-construct brick by brick the path that lead us to closing the loop in our Freedom Quilt unit. We hope that other methods course instructors may find our journey insightful.

\section{Acknowledgements}

P.E.C. extends sincere thanks and appreciation to former student Kelly Hauser who presented a lesson on symmetry and quilts in Math Methods years ago, and from which the current thematic integrated Freedom Quilt unit is based, and both L.C. and P.E.C. thank our current students for letting us travel this journey together and allowing us to dive deeper in this process.

\section{Conflicts of Interest}

The authors declare no conflicts of interest regarding the publication of this paper.

\section{References}

Accreditation as Quality Assurance (2013). Meeting the Needs of $21^{\text {st }}$ Century Learning. S. HRG. (pp. 113-823). Hearing of the Committee on Health, Education, Labor, and Pensions. United States Senate. $113^{\text {th }}$ Congress. First Session on Examining Accreditation as Quality Assurance: Meeting the Needs of $21^{\text {st }}$ Century Learning.

Anderson, J. R., Greeno, J. G., Kline, P. J., \& Neves, D. M. (1981). Acquisition of Problem-Solving Skill. In J. R. Anderson (Ed.), Cognitive Skills and Their Acquisition (pp. 191-230). Hillsdale, NJ: Erlbaum.

Anderson, L. W., Krathwohl, D. R., Airasian, P. W., Cruikshank, K. A., Mayer, R. E., Pintrich, P. R., Raths, J., \& Wittrock, M. C. (2001). A Taxonomy for Learning, Teaching, and Assessing: A Revision of Bloom's Taxonomy of Educational Objectives. New York: Longman.

Ansberry, K., \& Morgan, E. (2010). Picture-Perfect Science Lessons-Expanded $2^{\text {nd }}$ Edition: Using Children's Books to Guide Inquiry (pp. 3-6). Arlington, VA: National 
Science Teachers Association-NSTA Press.

Bakken, L., Clark, F. L., \& Thompson, J. (1998). Collaborative Teaching: Many Joys, Some Surprises, and a Few Worms. College Teaching, 46, 154-157. https://doi.org/10.1080/87567559809596263

Barta, J., Eglash, R., \& Barkley, C. (2014). Math Is a Verb: Activities and Lessons from Cultures around the World. Reston, VA: National Council of Teachers of Mathematics.

Benner, P. (1982). From Novice to Expert. American Journal of Nursing, 82, 402-407.

Bennett, I. J., \& Madden, D. J. (2014). Disconnected Aging: Cerebral White Matter Integrity and Age-Related Differences in Cognition. Neuroscience, 276, 187-205. https://doi.org/10.1016/j.neuroscience.2013.11.026

Bennett, I. J., \& Rypma, B. (2013). Advances in Functional Neuroanatomy: A Review of Combined DTI and fMRI Studies in Healthy Younger and Older Adults. Neuroscience \& Biobehavioral Reviews, 37, 1201-1210. https://doi.org/10.1016/j.neubiorev.2013.04.008

Bishop, A. J. (1988). Mathematical Enculturation: A Cultural Perspective on Mathematics Education. Dordrecht: Klewer Academic Publishers. https://doi.org/10.1007/978-94-009-2657-8

Bransford, J. D., Brown, A. L., \& Cocking, R. R. (2000). How People Learn: Brain, Mind, Experience, and School. Washington DC: National Academy Press.

Buckner, R. L., \& Koutstaal, W. (1998). Functional Neuroimaging Studies of Encoding, Priming, and Explicit Memory Retrieval. Proceedings of the National Academy of Sciences of the United States of America, 95, 891-989.

https://doi.org/10.1073/pnas.95.3.891

Chappuis, J. (2014). Thoughtful Assessment with the Learner in Mind. Educational Leadership, 71, 20-26.

Chase, W., G., \& Ericsson, K. A. (1981). Skilled Memory. In J. R. Anderson (Ed.), Cognitive Skills and Their Acquisition (pp. 141-189). Hillsdale, NJ: Erlbaum.

Coggins III, P. E. (2002). Corpus Callosum Variation in Pre-Adolescent Gifted and Talented Students. Doctoral Dissertation, University of Idaho, Abstracts International (UMI), Accession No: AA13043267.

Cole, M., \& Scribner, S. (1974). Culture \& Thought: A Psychological Introduction. New York: John Wiley \& Sons, Inc.

Cole, M., Gay, J., Glick, J. A., \& Sharp, D. W. (1971). The Cultural Context of Learning and Thinking: An Exploration in Experimental Anthropology. New York: Basic Books, Inc., Publishers.

Confrey, J. (1990). What Constructivism Implies for Teaching. [Monograph]. Journal for Research in Mathematics Education, 4, 107-124.

Creswell, J. (2015). Educational Research: Planning, Conducting, and Evaluating Quantitative and Qualitative Research (5th ed.). Boston, MA: Pearson.

Davachi, L., \& Dobbins, I. G. (2008). Declarative Memory. Current Directions in Psychological Science, 17, 112-118. https://doi.org/10.1111/j.1467-8721.2008.00559.x

de Groot, A. (1946). Het denken van den schaker: Een experimenteel-psychologische studie. Amsterdam: N.V. Noord-Hollandsche Uitgevers Maatschappij.

Elementary and Secondary Education Act (ESEA) (1965). Pub. L. No. 89-10 \$ 79. https://www.gpo.gov/fdsys/pkg/STATUTE-79/pdf/STATUTE-79-Pg27.pdf

Every Student Succeeds Act (ESSA) (2015-2016). Pub. L. No. 114-95 $\$ 114$ Stat. https://www.congress.gov/bill/114th-congress/senate-bill/1177 
Federal Aviation Administration (2003). Advisory Circular: General Aviation Controlled Flight into Terrain Awareness. AC No. 61-134, U.S. Department of Transportation. https://www.faa.gov/documentLibrary/media/Advisory_Circular/ac61-134.pdf

Fedorenko, E., Scott, T. L., Brunner, P., Coon, W. G., Pritchett, B., Schalk, G., \& Kanwisher, N. (2016). Neural Correlate of the Construction of Sentence Meaning. Proceedings of the National Academy of Sciences of the United States of America, 113, E6256-E6262. https://doi.org/10.1073/pnas.1612132113

Giedd, J. N., Blumenthal, J., Jeffries, N. O., Rajapakse, J. C., Vaituzis, A. C., Liu, H., \& Castellanos, F. X. (1999). Development of the Human Corpus Callosum during Childhood and Adolescence: A Longitudinal MRI Study. Progress in Neuro-Psychopharmacology \& Biological Psychiatry, 23, 571-588. https://doi.org/10.1016/S0278-5846(99)00017-2

Goertz, M. E., Olah, L. N., \& Riggan, M. (2009). Can Interim Assessments Be Used for Instructional Change? Policy Briefs RB-51, Consortium for Policy Research in Education. https://pdfs.semanticscholar.org/17e9/2c874965137414b77ebb2c33f2c23e3a96f2.pdf

Hammerness, K. M., Darling-Hammond, L., Bransford, J. et al. (2005). How Teachers Learn and Develop. In L. Darling-Hammond, \& J. Bransford (Eds.), Preparing Teachers for a Changing World: What Teachers Should Learn and Be Able to Do (pp. 358-389). San Francisco, CA: Jossey-Bass.

Hasan, K. M., Kamali, A., Iftikhar, A., Kramer, L. A., Papanicolaou, A. C., Fletcher, J. M., \& Ewing-Cobbs, L. (2009). Diffusion Tensor Tractography Quantification of the Human Corpus Callosum Fiber Pathways across the Lifespan. Brain Research, 1249, 91-100. https://doi.org/10.1016/j.brainres.2008.10.026

Hattie, J. (2003). Teachers Make a Difference: What Is the Research Evidence? Interpretations, 36, 27-38.

Hopkins, D. (1995). Sweet Clara and the Freedom Quilt. New York, NY: Random House Children's Books.

Jackson, S., \& Bohrer, J. (2010). Quality Assurance in Higher Education: Recent Developments in the United Kingdom. Research in Comparative and International Education, 5, 77-87. https://doi.org/10.2304/rcie.2010.5.1.77

Jakab, A., Tuura, R., Kellenberger, C., \& Scheer, I. (2017). In Utero Diffusion Tensor Imaging of the Fetal Brain: A Reproducibility Study. NeuroImage: Clinical, 15, 601-612. https://doi.org/10.1016/j.nicl.2017.06.013

Jakab, A., Tuura, R., Kellenberger, C., \& Scheer, I. (2017). In Utero Diffusion Tensor Imaging of the Fetal Brain: A Reproducibility Study. NeuroImage: Clinical, 15, 601-612. https://doi.org/10.1016/j.nicl.2017.06.013

Jeffries, R., Turner, A. A., Polson, P. G., \& Atwood, M. E. (1981). The Processes Involved in Designing Software. In J. R. Anderson (Ed.), Cognitive Skills and Their Acquisition (pp. 255-283). Hillsdale, NJ: Erlbaum.

Jellison, B. J., Field, A. S., Medow, J., Lazar, M., Shariar Salamat, M., \& Alexander, A. L. (2004). Diffusion Tensor Imaging of Cerebral White Matter: A Pictoral Review of Physics, Fiber Tract Anatomy, and Tumor Imaging Patterns. American Journal of Neuroradiology, 25, 356-369.

Jenkins, L. E., \& Crawford, R. (2016). The Impact of Blended Learning and Team Teaching in Tertiary Pre-Service Music Education Classes. Journal of University Teaching \& Learning Practice, 13, 1-23.

John, Y. J. (2015). A “New” Thematic, Integrated Curriculum for Primary Schools of Trinidad and Tobago: A Paradigm Shift. International Journal of Higher Education, 4, 172-187. https://doi.org/10.5430/ijhe.v4n3p172 
Keshavan, M. S., Diwadkar, V. A., DeBellis, M., Dick, E., Kotwal, R., Rosenberg, D. R., \& Pettegrew, J. W. (2002). Development of the Corpus Callosum in Childhood, Adolescence and Early Adulthood. Life Sciences, 70, 1909-1922. https://doi.org/10.1016/S0024-3205(02)01492-3

Kline, M. (1962). Mathematics: A Cultural Approach. Reading, MA: Addison-Wesley Publishing Company, Inc.

Kruger, J., \& Dunning, D. (1999). Unskilled and Unaware of It: How Difficulties in Recognizing One's Own Incompetence Lead to Inflated Self-Assessments. Journal of Personality and Social Psychology, 77, 1121-1134. https://doi.org/10.1037/0022-3514.77.6.1121

Lester, J. N., \& Evans, K. R. (2009). Instructors' Experiences of Collaboratively Teaching: Building Something Bigger. International Journal of Teaching and Learning in Higher Education, 20, 373-382.

Luria, A. R. (1976). Cognitive Development: Its Cultural and Social Foundations. Cambridge, MA: Harvard University Press.

Maclelan, E. (2004). Initial Knowledge States about Assessment: Novice Teachers' Conceptualizations. Teaching and Teacher Education, 20, 523-535.

https://doi.org/10.1016/j.tate.2004.04.008

Madden, D. J., Bennett, I. J., Burzynska, A., Potter, G. G., Chen, N., \& Song, A. W. (2012). Diffusion Tensor Imaging of Cerebral White Matter Integrity in Cognitive Aging. Biochimica et Biophysica Acta, 1822, 386-400. https://doi.org/10.1016/j.bbadis.2011.08.003

Morrison, J. (2008/9). Why Teachers Must Be Data Experts. Educational Leadership, 66.

Noddings, N. (1990). Constructivism in Mathematics Education. Journal for Research in Mathematics Education, 4, 7-18.

O’Donnell, J. J., Kubicki, M., Shenton, M. E., Dreusicke, M. H., Grimson, W. E. L., \& Westin, C. F. (2006). A Method for Clustering White Matter Fiber Tracts. American Journal of Neuroradiology, 27, 1032-1036.

Park, J. K., Kim, B. S., Choi, G., Kim, S. H., Choi, J. C., \& Khang, H. (2008). Evaluation of the Somatotopic Organization of Corticospinal Tracts in the Internal Capsule and Cerebral Peduncle: Results of Diffusion-Tensor MR Tractography. Korean Journal of Radiology, 9, 191-195. https://doi.org/10.3348/kjr.2008.9.3.191

Persky, A. M., \& Robinson, J. D. (2017). Moving from Novice to Expertise and Its Implications for Instruction. American Journal of Pharmaceutical Education, 81, 72-80.

Plano Clark, V. L., \& Creswell, J. W. (2015). Understanding Research: A Consumer's Guide. Boston, MA: Pearson.

Qiu, A., Mori, S., \& Miller, M. I. (2015). Diffusion Tensor Imaging for Understanding Brain Development in Early Life. Annual Review of Psychology, 66, 853-876. https://doi.org/10.1146/annurev-psych-010814-015340

Reeves, D. B. (2008/2009). The Learning Leader/Looking Deeper into the Data. Educational Leadership, 66, 89-90.

Remesal, A. (2011). Primary and Secondary Teachers' Conceptions of Assessment: A Qualitative Study. Teaching and Teacher Education, 27, 472-482.

Ryan, T. (2015). Quality Assurance in Higher Education: A Review of the Literature. Higher Learning Research Communications, 5. https://doi.org/10.18870/hlrc.v5i4.257 https://files.eric.ed.gov/fulltext/EJ1132941.pdf

Saxe, G. B. (1991). Culture and Cognitive Development: Studies in Mathematical Understanding. Hillsdale, NJ: Lawrence Erlbaum Associates, Publishers. 
Scimeca, J. M., \& Badre, D. (2012). Striatal Contributions to Declarative Memory Retrieval. Neuron, 75, 380-392. https://doi.org/10.1016/j.neuron.2012.07.014

Shanteau, J. (1992). Competence in Experts: The Role of Task Characteristics. Organizational Behavior and Human Decision Processes, 53, 252-266. https://doi.org/10.1016/0749-5978(92)90064-E

Sheridan, H., \& Reingold, E. M. (2014). Expert vs. Novice Differences in the Detection of Relevant Information during a Chess Game: Evidence from Eye Movements. Frontiers in Psychology, 5, 1-6.

Smagorinsky, P., Cook, L. S., \& Johnson, T. S. (2003). The Twisting Path of Concept Development in Learning to Teach. Report Series 16002. The National Research Center on English Learning \& Achievement.

Tanaka-Arakawa, M. M., Matsui, M., Tanaka, C., Uematsu, A., Uda, S., Miura, K., \& Noguchi, K. (2015). Developmental Changes in the Corpus Callosum from Infancy to Early Adulthood: A Structural Magnetic Resonance Imaging Study. PLoS One, 10, e0118760.

U.S. Department of Education (2008). U.S. Network for Education Information. https://www2.ed.gov/about/offices/list/ous/international/usnei/us/edlite-accreditation. $\underline{\mathrm{html}}$

Von Glasersfeld, E. (1989). Constructivism in Education. In T. Husen, \& T. N. Postlethwaite (Eds.), The International Encyclopedia of Education (pp. 162-163, Vol. 1). Oxford/New York: Pergamon Press.

Vygotsky, L. S. (1978). Mind in Society: The Development of Higher Psychological Processes. Cambridge, MA: Harvard University Press.

Ward, R. A. (2009). Literature-Based Activities for Integrating Mathematics with Other Content Areas. Boston, MA: Allyn and Bacon.

Weiss, M. P., Pellegrino, A., Regan, K., \& Mann, L. (2015). Beyond the Blind Debate: Collaborative Course Development and Co-Teaching by Teacher Educators. Teacher Education and Special Education, 38, 88-104. https://doi.org/10.1177/0888406414548599

Whorf, B. L. (1956). Thought, Language, Reality: Selected Writings. Cambridge, MA: The Massachusetts Institute of Technology.

Wilson, V. A., \& Martin, K. M. (1998). Practicing What We Preach: Team Teaching at the College Level. 